\title{
Effect of orally administered nadolol on the intraocular pressure in normal volunteers
}

\author{
JOHN WILLIAMSON, H R ATTA, P A KENNEDY, AND J G MUIR \\ From the Department of Ophthalmology, Southern General Hospital, Govan Road, Glasgow G51 4TF
}

SUMMARY Forty six normal volunteers were randomly assigned in double-blind fashion to once daily orally administered nadolol $10,20,40$, or $80 \mathrm{mg}$ for five days. Significant and dose related intraocular pressure (IOP) reductions (range 20-40\%) were demonstrated both at three hours and 24 hours post dosing $(\mathrm{p}<0.001$, all dosages $)$. The reductions in IOP were dose related $(\mathrm{p}<0 \cdot 05)$. One subject (in the $10 \mathrm{mg}$ group) failed to show a significant intraocular pressure reduction. Significant reductions in blood pressure and heart rate also were recorded at all dose levels (with the exception of diastolic pressure in the $10 \mathrm{mg}$ group), though considerably less in degree than IOP reductions. Two subjects ( $20 \mathrm{mg}$ and $80 \mathrm{mg}$ groups) experienced known side effects of $\beta$ blocker therapy necessitating termination of the drug, and four others experienced mild side effects but had no difficulty completing the study. The results have prompted further investigation of the usefulness of low doses of oral nadolol as therapy in chronic simple glaucoma patients.

Since 1967 when Phillips et al. first demonstrated the ocular hypotensive effect of propranolol,' it has been shown that most $\beta$ blockers, given either topically or systemically, can lower intraocular pressure (IOP) to varying degrees in either normal or glaucomatous eyes. ${ }^{2}$ The mechanism of action is not clear, but blockade of the $\beta$ receptors in the ciliary body appears to decrease aqueous inflow. ${ }^{3}$ Recent work (J. Williamson) indicates that these receptors are mostly of the $\beta 2$ type, which might explain why the IOP lowering action of propranolol and timolol (nonselective blockade) is maintained in the long term, whereas the action of atenolol ( $\beta 1$ blockade) appears to wane during chronic administration. ${ }^{4}$

Nadolol is a non-selective $\beta$ blocking agent with the longest half life of this class of compound (20-24 hours) and thus is suitable for once daily administration. ${ }^{5}$ This study was designed to determine the degree and duration of the ocular hypotensive effect of four dose strengths of oral nadolol $(10,20,40$, and $80 \mathrm{mg}$ ) in normal volunteers with a view to ascertaining whether, and at what doses, once daily nadolol administration might be useful in the treatment of glaucoma. In view of the increasing number of patients on chronic $\beta$ blocker therapy for a variety of reasons-including, in our experience, many in the glaucoma clinic population-the results might have clinical implications.

Correspondence to J Williamson, MD.

\section{Materials and methods}

Subjects. A group of 46 normal adult volunteers (32 men, 14 women), mean age 25 years (range 19 to 58 ), participated in this study. Prior to entry all subjects underwent a general physical examination and had intraocular pressures in each eye recorded by Goldmann applanation tonometry. Subjects were excluded for the following reasons: pretreatment hypertension (diastolic pressure $>90 \mathrm{mmHg}$, systolic pressure $>140 \mathrm{mmHg}$ ); raised pretreatment IOP ( $>21 \mathrm{mmHg}$ in either eye); history of heart disease, asthma, or bronchospasm; impaired renal or hepatic function; receiving other medication that could affect IOP; pregnancy or women of childbearing age not practising adequate methods of contraception. All subjects were made fully aware of the conditions and drugs used in the study and provided informed consent. The study protocol was approved by the hospital's Ethics Committee.

Procedure. The active treatment phase of this study was conducted in double-blind fashion. The 46 subjects satisfying the criteria for entry were randomised into four treatment groups one group for each of the four nadolol dose levels studied $(10,20$, 40 , and $80 \mathrm{mg}$ daily). Each treatment group progressed through four periods as follows:

$$
\begin{array}{lccc}
\text { Day 0-7 } & \text { Day 8-12 } & \text { Day 13-15 } & \text { Day 16-22 } \\
\text { Placebo } & \text { Nadolol } & \text { Nadolol step down } & \text { Placebo }
\end{array}
$$


The investigators were aware of placebo and nadolol periods but not of nadolol potencies. (Double-blind supplies of nadolol and matching placebo were made available by the manufacturer, E. R. Squibb and Sons Ltd.)

Following the initial assessment and enrolment visits were made on days 3 and 7 of the pretreatment placebo period, days 8 through 12 (active treatment), day 15 (completion of dosage step down), and days 16 through 22 (post-treatment placebo period). Visits were timed to occur approximately three hours after the morning dose of medication except for one visit on either day 10 or 11 during active treatment, when the visit was timed to take place 23 to 24 hours following the previous day's dose.

At each visit IOP was measured by Goldmann applanation tonometry, and blood pressure and pulse rate were recorded after five minutes in the supine position. One person was responsible for both tonometric and vital sign measurements throughout the study. Measurements recorded on days three and seven were averaged and considered as baseline values. On day seven, and at the end of the full nadolol dosage period (day 12), the following further measurements were made: visual acuity, amplitude of accommodation, pupil diameter, and refraction.

During the nadolol dosage step down period the dosage of the 40 and $80 \mathrm{mg}$ groups was halved. The dosage of subjects receiving 10 and $20 \mathrm{mg}$ daily continued unchanged.

\section{Results}

Forty two of the 46 subjects completed the 22-day study. One subject withdrew during the placebo period for personal reasons. Three others withdrew towards the end of the treatment period because of side effects (2) and concomitant illness (1) but provided data suitable for evaluation.

The IOP lowering effect of the four dose strengths of nadolol is shown in Table 1. The average for both eyes of all IOP measurements taken three hours after the dose (excluding the first nadolol dose, that is day 8 ) shows a mean percentage IOP reduction from baseline of $29 \cdot 5,36 \cdot 4,36 \cdot 9$, and $41 \cdot 0 \%$ with the 10 , 20,40 , and $80 \mathrm{mg}$ doses respectively $(\mathrm{p}<0.001$ for each dose level). Only one subject in the trial $(10 \mathrm{mg}$ group) failed to show a significant IOP reduction. The log dose response when adjusted for baseline differences demonstrated that pressure reductions were significantly dose related $(p<0 \cdot 05)$.

Large and statistically significant pressure reductions also were demonstrated 23-24 hours after dosing (Table 2 ). These were respectively $21 \cdot 1,22 \cdot 2$, $30 \cdot 0$, and $39 \cdot 7 \%$ with the $10,20,40$, and $80 \mathrm{mg}$ doses $(p<0.001$ for each dose level). The attenuation of the hypotensive response at 23-24 hours was statistically significant in the 10 and $20 \mathrm{mg}$ groups $(\mathrm{p}<0.05$ and $\mathrm{p}<0.01$ respectively).

Reductions in systolic pressure, diastolic pressure, and pulse rate ranged from 5 to $11 \%, 4$ to $11 \%$, and 17 to $20 \%$ respectively. With the exception of the diastolic pressure in the $10 \mathrm{mg}$ group these reductions were statistically significant at all dose levels (range $\mathrm{p}<0.05-<0.001$ ), and, in the case of systolic and diastolic pressure, showed a significant dose response relationship $(p<0.05)$. The relative effects on the eye and the cardiovascular system are shown graphically in Fig. 1. Reductions in IOP were twice those of heart rate and more than three times those of systolic and diastolic blood pressure. In all four dosage groups both vital signs and IOP returned to baseline levels during the final placebo period.

Two subjects $(4 \cdot 4 \%)$ were discontinued because of

Table 1 Mean IOP change from baseline three hours post dose among normal subjects receiving different doses of oral nadolol: results averaged over three treatment days

\begin{tabular}{|c|c|c|c|c|c|c|}
\hline Dose mg & $n$ & Baseline IOP $\mathrm{mmHg}$ & Treatment IOP $\mathrm{mmHg}$ & IOP reduction $\mathrm{mm} H \mathrm{~g}$ & $\%$ IOP reduction & $p$ value \\
\hline 10 & 12 & $15 \cdot 6$ & $11 \cdot 0$ & $4 \cdot 6$ & 29.5 & $<0 \cdot(0) 1$ \\
\hline 20 & 11 & $16 \cdot 2$ & $10 \cdot 3$ & 5.9 & 36.4 & $<0.001$ \\
\hline 40 & 11 & $15 \cdot 7$ & 9.9 & $5 \cdot 8$ & 36.9 & $<0.001$ \\
\hline 80 & 11 & $15 \cdot 6$ & 9.2 & 6.4 & $41 \cdot 0$ & $<0.001$ \\
\hline
\end{tabular}

Table 2 Mean IOP change from baseline 23-24 hours post dose among normal subjects receiving different doses of oral nadolol: results obtained at one visit after at least three days active therapy

\begin{tabular}{|c|c|c|c|c|c|c|}
\hline Dose mg & $n$ & Baseline IOP $\mathrm{mmHg}$ & Treatment IOP $\mathrm{mmHg}$ & IOP reduction $\mathrm{mm} \mathrm{Hg}$ & $\% I O P$ reduction & $p$ value \\
\hline 10 & 11 & $15 \cdot 6$ & $12 \cdot 3$ & $3 \cdot 3$ & $21 \cdot 1$ & $<0.001$ \\
\hline 20 & 10 & $16 \cdot 2$ & $12 \cdot 6$ & $3 \cdot 6$ & $22 \cdot 2$ & $<0.001$ \\
\hline 40 & 11 & $15 \cdot 7$ & $11 \cdot 0$ & $4 \cdot 7$ & $30 \cdot 0$ & $<0 \cdot 001$ \\
\hline 80 & 10 & $15 \cdot 6$ & 9.4 & $6 \cdot 2$ & 39.7 & $<0 \cdot 001$ \\
\hline
\end{tabular}




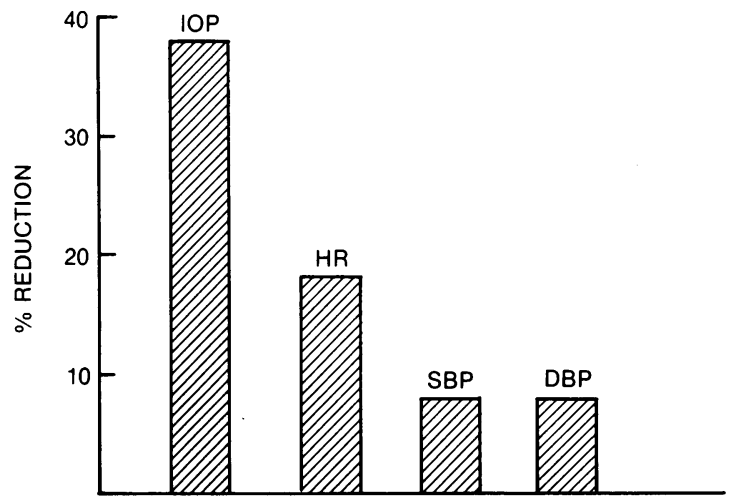

Fig. 1 Relative reductions in intraocular pressure (IOP), systolic pressure $(S B P)$, diastolic pressure $(D B P)$, and heart rate $(H R)$ for all doses combined.

side effects associated with $\beta$ blockade. One, a 45-year-old man receiving $20 \mathrm{mg}$, developed bradycardia ( 42 beats per minute); the other, a 48 -year-old woman in the $80 \mathrm{mg}$ group, experienced breathlessness, tiredness, and dry mouth. Mild side effects were reported by a further four subjects $(8.9 \%)$ : two cases of fatigue (20 and $80 \mathrm{mg}$ groups), one case of slight nausea ( $20 \mathrm{mg}$ group), and one episode of dizziness in a subject in the $40 \mathrm{mg}$ group.

Oral nadolol treatment had no effect on the ocular parameters of visual acuity, accommodation, pupil size, and refraction.

\section{Discussion}

The ocular hypotensive effect of orally administered nadolol in normal subjects at all dose levels employed in this study was considerable, even after 24 hours. The IOP reductions observed with low to modest doses of nadolol appear to be of greater magnitude than those previously reported in normal volunteers following the oral use of both atenolol and propranolol in corresponding, and higher, doses. ${ }^{67}$

Oral nadolol was well tolerated with only two patients $(4 \cdot 4 \%)$ being discontinued for side effects common to $\beta$ blockers. The pulse rate reductions of $17-20 \%$ were impressive, but even with topical timolol administered twice daily to both eyes pulse rate reductions approximating $14 \%$ may be experienced. ${ }^{\mathrm{x}}$

Our results indicate that 20 and $40 \mathrm{mg}$ once daily oral doses of nadolol (less than the usual starting dose of $80 \mathrm{mg}$ in hypertension) may have a therapeutic role in the management of glaucoma. Furthermore an increasing number of patients-including, in our experience, a growing percentage of those in the glaucoma clinic population-already are receiving oral $\beta$ blockers for cardiovascular indications. Thus there is a subset of glaucoma patients who present the possibility of having their $\beta$ blocker therapy rationalised to treat two diseases.

From our results in normal subjects we decided to study the use of once daily oral nadolol in patients with chronic simple glaucoma. ${ }^{9}$

\section{References}

1 Phillips CI, Howitt G, Rowlands DJ. Propranolol as ocular hypotensive agent. BrJ Ophthalmol 1967; 51: 222-6.

2 Wettrell K. Pandolfi M. Beta-adrenoceptor blocking agents in the management of glaucoma. In: Bellow JG, ed. Glaucoma manual. New York: Masson, 1979; 367-75.

3 Thomas JV, Epstein DL. Timolol and epinephrinc in primary open-angle glaucoma. Arch Ophthalmol 1971; 99: 91-5.

4 Brenkman RF. Long-term hypotensive effect of atenolol $4 \%$ cycdrops. Br J Ophthalmol 1978; 62: 287-91.

5 Frishman W. Clinical pharmacology of the new beta-adrenergic blocking drugs. Part 9. Nadolol: a new long-acting betaadrenoceptor blocking drug. Am Heart J 1980; 99: 124-8.

6 Wettrell K, Pandolfi M. Effect of oral administration of various beta-blocking agents on the intraocular pressure in healthy voluntecrs. Exp Eye Res 1975; 21: 451-6.

7 Ohrstrom A, Pandolfi M. Regulation of intraocular pressure and pupil size by $\beta$-blockers and cpincphrinc. Arch Ophthalmol 1980; 98: $2182-4$

8 Boger WP. Puliafito CA, Steinert RF, Langston DP. Long-term experience with timolol ophthalmic solution in patients with openangle glaucoma. Ophthalmology 1978; 85: 259-67.

9 Williamson J, Young JDH, Atta H. Muir G, Kadom H. Comparative efficacy of orally and topically administered $\beta$ blockers for chronic simple glaucoma. BrJ Ophthalmol 1985; 69: 41-5. 